\title{
Prevalence and Study of Antibiotic Resistant Pattern of Salmonella in Raw Milk
}

\author{
R.M. Dhingani", B.H. Joshi and R.V. Prasad \\ Department of Food Quality Assurance, College of Food Processing Technology and Bio- \\ Energy, Anand Agricultural University, Anand-388110, Gujarat, India \\ *Corresponding author
}

\section{A B S T R A C T}

Keywords

Raw milk,

Salmonellosis, RT-

PCR, Antibiotic

susceptibility and

pasteurization

Article Info

Accepted:

12 March 2018

Available Online:

10 April 2018
Salmonellosis is one of the most commonly reported food borne disease all over the world and developing countries. This study was conducted to determine the prevalence of Salmonella spp. in raw milk. Isolation and identification of Salmonella was carried out using real time polymerase chain reaction (RT-PCR) technique and sensitivity tests were done by the Kirby-Bauer disc diffusion method. Total of 70 raw milk samples were collected from the 5 different dairy farms. The prevalence of Salmonella spp. in raw milk of the study area was $8.57 \%$. This study reveals that collected Salmonella spp. were susceptible to antibiotics and also heat sensitive at pasteurization process which ensures the safety of pasteurized milk against Salmonella spp.

\section{Introduction}

Milk is an essential part of daily diet for the growing children. It has been described as a nearly perfect food because it contains the essential nutrients required by the body in appropriate proportions.

However, the safety of milk and dairy products with respect to food-borne diseases is a major global issue especially in the developing countries where production of milk and milk product takes place under poor hygienic, sanitary and agricultural practices (Jordan, 2007).
Raw milk and milk products are increasingly becoming important sources of human infection with Salmonella.

It is major pathogenic bacteria that cause salmonellosis on human being and other organisms in the world (Mrema et al., 2006).

Salmonellosis is one of the major zoonotic diseases all over the world with annual estimates of 22 million cases and 200,000 deaths due to typhoid fever (Crump, et al., 2004) and 93.8 million cases of gastroenteritis and 155000 deaths due to non-typhoidal Salmonellae (NTS) (Majowicz, et al., 2010). 
Salmonella includes more than 2500 different serotypes represents a leading cause of foodborne infections worldwide. The majority of the infections are associated with ingestion of contaminated foods such as poultry, beef, egg, milk, cheese, seafood, fruits, juice and vegetables (Brands et al., 2005; Zhao et al., 2008). The distribution of Salmonella can vary greatly depending on the Serovars. Species such as Salmonella enterica serotype Enteritidis and Salmonella enterica serotype Typhimurium have established global niches (Ellermeier and Slauch, 2006). Salmonella infection is generally self-limiting illness, but severe cases in immuno-compromised individuals, elderly persons or neonates, and systemic infections may require effective chemotherapy.

Traditional microbiological methods offered standardized procedures for microbial detection. However, they are time consuming, laborious and not always compatible with short-time-to-result demand. Therefore, food microbiology aims for supplementation of classical methods with molecular techniques based on detection of the nucleic acids, which shorten the analysis time and lower the limit of detection (Kusar et al., 2010). Since Salmonella was closely related to both public and animal health, more rapid and sensitive methods for the identification of these bacteria are required. RT-PCR technology offers several advantages compared with classical bacteriology in terms of speed, detection limit, potential for automation and cost.

The development of antimicrobial resistance among bacteria (AMR) is currently one of the world's most pressing public health problems. The World Health Organization (WHO) has reported as increase in the incidence of antibiotic resistant strains of Salmonella due to the use of antibiotics as treatment and prophylaxis frequently around the world WHO (2010). Misuse of antimicrobial agents both in humans and animals has narrowed the potential use of antibiotics for the treatment of infections in humans. To monitor the evolution of AMR and to develop control measures, some countries, have set up national integrated monitoring systems.

Similarly, with Salmonella being an important cause of food-borne diarrheal disease in human beings, the reduction in the number of antibiotics available for effective treatment of Salmonella related infectious diseases in humans and animals has become a serious concern. The frequency and extent of the resistance to antimicrobials by Salmonella vary based on the antimicrobial usage in humans and animals and the ecological differences in the epidemiology of Salmonella infections.

Thus, the aim of this project was to study prevalence and antimicrobial resistance pattern of Salmonella from the raw milk.

\section{Materials and Methods}

\section{Sample collection}

The study was conducted in region of Anand and its surrounding area of Gujarat, India. Samples of raw milk were collected aseptically in sterilized $500 \mathrm{ml}$ screw capped bottle from five different dairies at different time interval. Collected samples were transported to laboratory under cooling condition and temporarily kept under refrigerator at $4^{\circ} \mathrm{C}$ until processed further.

\section{Sample enrichment}

Within 2 to $6 \mathrm{~h}$ of collection, $25 \mathrm{ml}$ of collected samples were homogenized with 225 $\mathrm{ml}$ of non-enrichment buffered peptone medium (peptone: $10 \mathrm{~g}$; sodium chloride: $5 \mathrm{~g}$; disodium hydrogen orthophosphate. $12 \mathrm{H}_{2} \mathrm{O}: 9$ g; potassium dihydrogen orthophosphate: 
$1.5 \mathrm{~g}$; deionized water to: $1000 \mathrm{ml} ; \mathrm{pH}: 7 \pm$ 0.2 ). In stomacher bag and incubated at $37^{\circ} \mathrm{C} \pm 1$ for $24 \mathrm{~h}$.

\section{DNA extraction and purification}

DNA was extracted from the pre-enrichment broth using iQ-Check Salmonella II kit (BioRad) following the manufacturer instruction; One $\mathrm{ml}$ of enriched samples were collected into sterile tubes from the pre-enrichment broth and centrifuged at 10,000 rpm for $5 \mathrm{~min}$. Supernatant discarded and $200 \mu \mathrm{l}$ of lysis reagent added in to the pellet and mixed it well. For incubation it was placed in water bath at $95^{\circ} \mathrm{C}$ for $15 \mathrm{~min}$. After incubation period it was centrifuged at $10,000 \mathrm{rpm}$ for 5 min. After centrifugation, supernatant $(5 \mu \mathrm{l})$ were used as a sample.

\section{Sample preparation for PCR}

Total $50 \mu \mathrm{l}$ of PCR mixture were prepared; 5 $\mu l$ of sample were mixed with $40 \mu \mathrm{l}$ of amplification mix (containing taq polymerase, buffer, dNTPs, $\mathrm{MgCl}_{2}$ and primers) and $5 \mu \mathrm{l}$ of fluorescent probe (Fig. 2).

\section{PCR setup}

PCR mix were amplified and analyzed along with the positive and negative control by CFX 96 Real Time System with C1000 Touch Thermal Cycler.

\section{Antibiotic resistance pattern of Salmonella}

The antimicrobial susceptibility testing for Salmonella isolates were carried out following the Kirby- Bauer's disc diffusion method as described in the guidelines of National Committee for Clinical Laboratory Standards (NCCLS). The Salmonella isolates were tested against following antibiotics; ampicillin (10 $\mu \mathrm{g})$, gentamicin $(10 \mu \mathrm{g})$, nalidixic acid (30 $\mu \mathrm{g})$, chloramphenicol $(30 \mu \mathrm{g})$, cefalexin (30 $\mu \mathrm{g})$ and co-trimoxazole $(25 \mu \mathrm{g})$. A standard suspension of active culture prepared in sterile $\mathrm{N}$-saline and it was spread on nutrient agar plate. The antibiotic hexavalent disc was dispensed on the medium and incubated at $35^{\circ} \mathrm{C}$ for $18 \mathrm{~h}$ and zone of inhibition was measured.

\section{Heat resistant profile of Salmonella}

Heat resistant profile of the selected Salmonella isolates was studied by exposing all the isolates at $62.8^{\circ} \mathrm{C}$ for $30 \mathrm{~min}$.

\section{Results and Discussion}

\section{Sample collection}

Total of 70 raw milk samples were collected from the different places for the prevalence study of Salmonella as depicted in Figure 1.

\section{Identification of Salmonella}

Real Time Polymerase Chain Reaction techniques were used for the identification Salmonella by using CFX 96 real time system with C1000 touch thermal cycler (Fig. 3).

From the five different regions 70 samples of raw milk were collected. Out of it 6 raw milk samples were found to be contaminated with Salmonella (Figure 4). Isolates collected from the contaminated samples were further tested for antibiotic and heat resistance profile.

\section{Antibiotic resistance profile of Salmonella}

Salmonella isolated from contaminated raw milk were subjected for antibacterial resistance profile studies as per the guidelines of National Committee for Clinical Laboratory Standards (NCCLS). The study reveals that all selected isolates were sensitive to selected antibiotics as shown in Figure 5. 
Fig.1 Collection of raw milk from different region

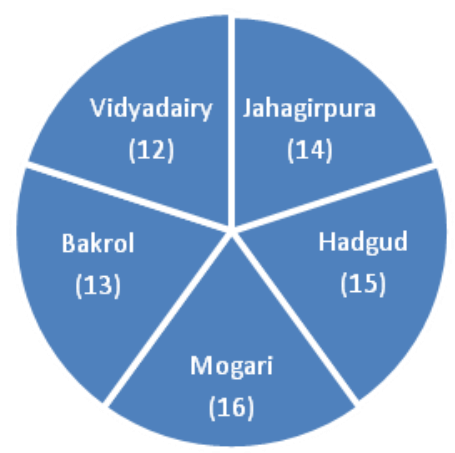

Fig.2 Amplification protocol for Salmonella DNA by using RT-PCR

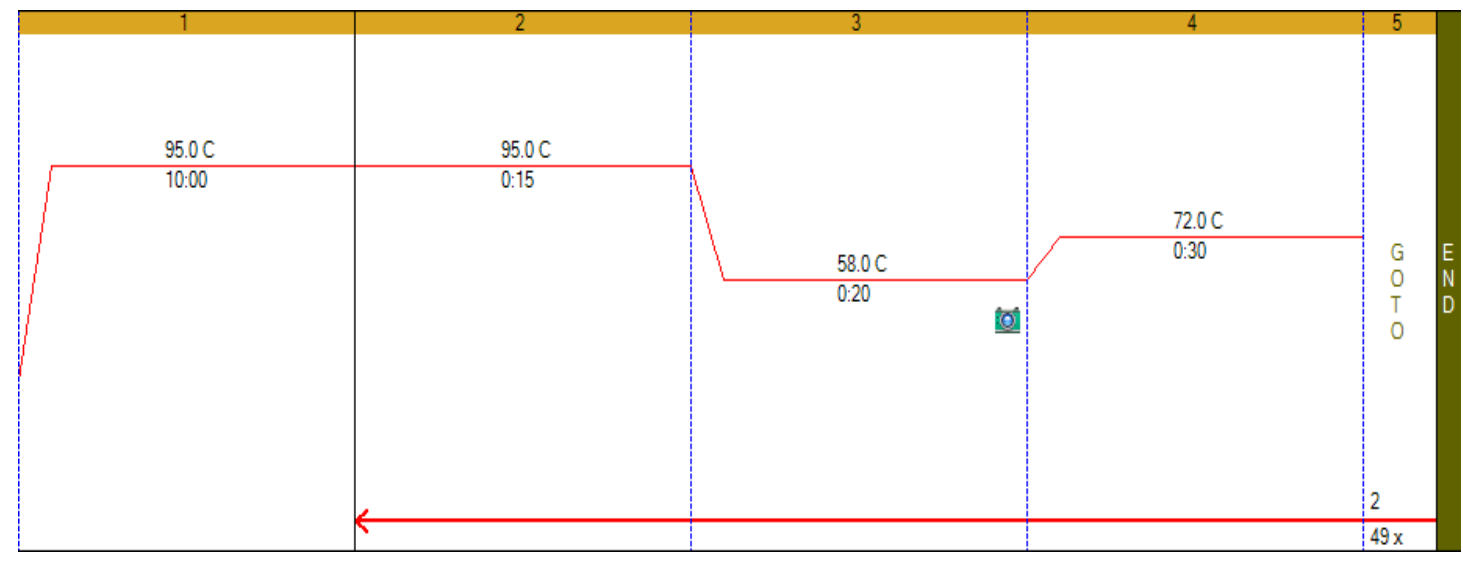

Fig.3 DNA Amplification curve with cT value of Salmonella

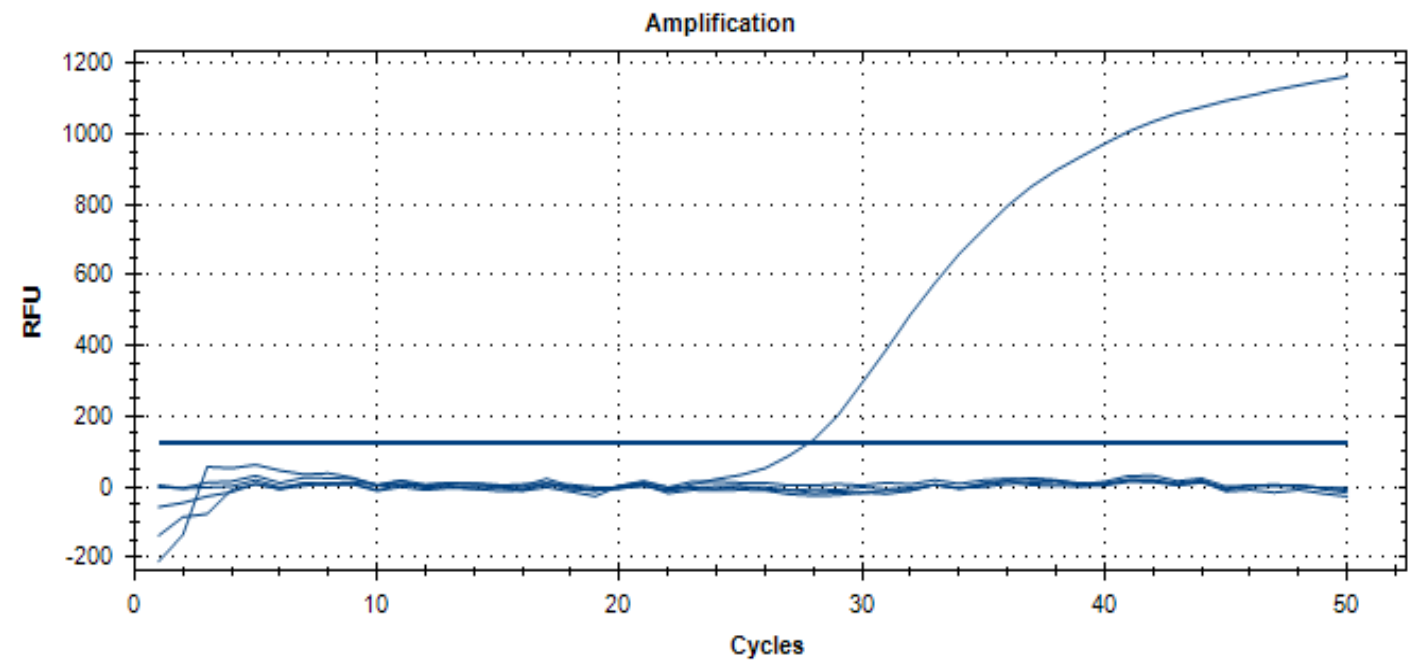


Fig.4 Distribution of Salmonella in raw milk

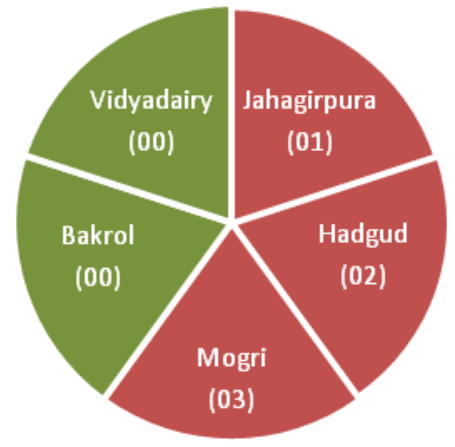

Fig.5 Antimicrobial resistant profile of Salmonella isolates obtained from raw milk

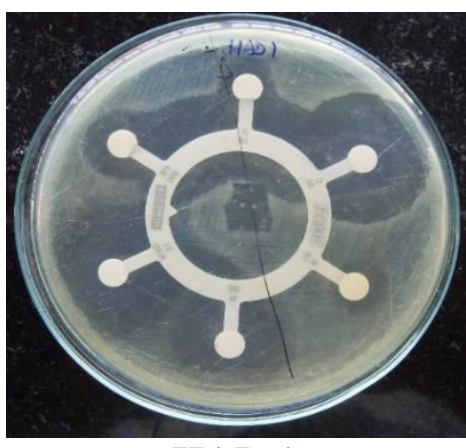

HAD 1

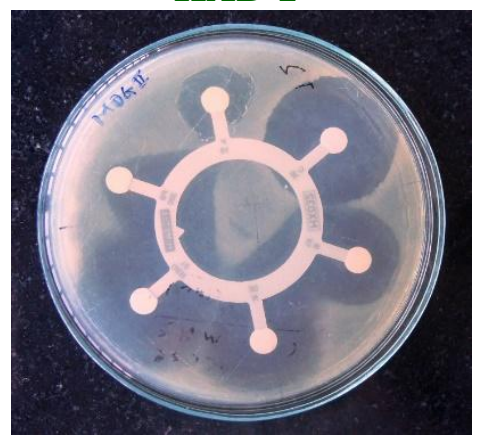

MOG 2

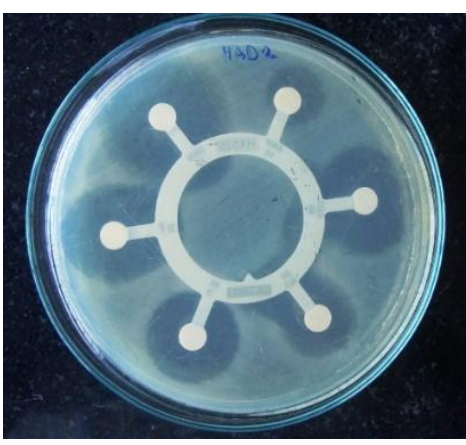

HAD 2

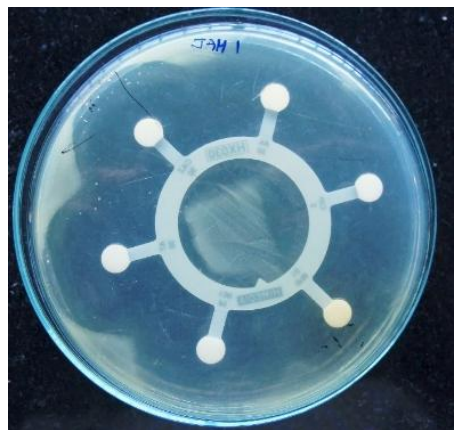

JAH 1

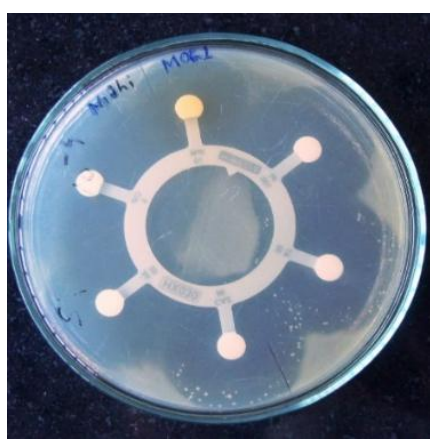

MOG 1

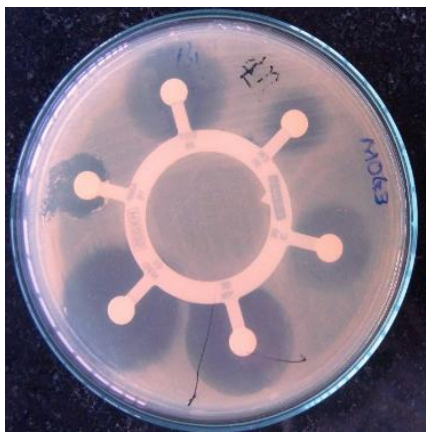

MOG 3

\section{Heat resistant profile of Salmonella}

These antibiotic sensitive isolates of Salmonella were also evaluated for its heat resistant profile by exposing them at $62.8^{\circ} \mathrm{C}$ for $30 \mathrm{~min}$. None of the isolates were found heat resistant at temperature above pasteurization process.

In conclusion, total of 70 samples of raw milk were evaluated for prevalence of Salmonella procured from five different regions of Anand district of Gujarat. Out of that only 6 samples were found to be contaminated with Salmonella reveals $8.57 \%$ prevalence. All the six collected Salmonella species were antibiotic sensitive and none of them shown resistance at pasteurization temperature. This ensures the safety of pasteurized milk against Salmonella prevalent in Anand region of Gujarat. 


\section{References}

Brands DA, Inman AE, Gerba CP, Mare CJ, Billington SJ, Saif LA, Levine JF, Joens LA. 2005. Prevalence of Salmonella spp. in oysters in the United States. Appl. Environ. Microbiol. 71, 893-897.

Charlotta Lofstrom, Michael Krause, Mathilde H Josefsen, Flemming Hansen and Jeffrey Hoorfar. 2009. Validation of a same day real-time PCR method for screening of meat and carcass swabs for Salmonella. BMC Microbiol. 9, 85.

Crump JA, Luby SP, Mintz ED. 2004. The global burden of typhoid fever. Bull World Health Organ. 82(5):346-353.

Ellermeier CD and Slauch JM. 2006. Genus Salmonella. In: Dworkin, M.D. The Prokaryotes: A Handbook on the Biology of Bacteria. Springer Press. New York.

Jordan D. 2007. Antimicrobial resistance in animals and impacts on food safety and public health. Infections. 28(4): 163164.

Kusar D, Pate M, Micunovic J, Hribovsek VB, Ocepek M. 2010. Detection of
Salmonella in poultry faces by molecular means in comparison to traditional bacteriological methods. Slov. Vet. Res. 47(2):45-56.

Majowicz SE, Musto J, Scallan E, Angulo FJ, Kirk M, O'Brien SJ, Jones TF, Fazil A, Hoekstra RM. 2010. The global burden of nontyphoidal Salmonella gastroenteritis. Clin. Infect. Dis. 50: 882-889.

Mrema N, Mpuchane S and Gashe BA. 2006. Prevalence of Salmonella in raw meat minced meat, raw fresh sausage and burger patties from retail outlets in Gaborone, Botswana. Food Control, 17: 207-212.

World Health Organization (WHO). 2010. Antimicrobial susceptibility of Salmonella enterica serovars in a tertiary care hospital in southern India. Indian J. Med. Res. 137: 800-802.

Zhao S, White, DG, Friedman SL, Glenn A, Blickenstaff K, Ayers SL, Abbott JW, Hall-Robinson E, McDermott PF. 2008. Antimicrobial resistance in Salmonella enteric serovar Heidelberg isolates from retail meats, including poultry. Appl. Environ. Microbiol. 74, 6656-6662.

\section{How to cite this article:}

Dhingani, R.M., B.H. Joshi and Prasad, R.V. 2018. Prevalence and Study of Antibiotic Resistant Pattern of Salmonella in Raw Milk. Int.J.Curr.Microbiol.App.Sci. 7(04): 1732-1737. doi: https://doi.org/10.20546/ijcmas.2018.704.197 